九州大学学術情報リポジトリ

Kyushu University Institutional Repository

\title{
Fire Retardant Performance and Thermal Degradation of Korean Pine Treated with Fire Retardant Chemical
}

Park, Hee-Jun

Department of Housing Environmental Design, and Research Institute of Human Ecology, College of Human Ecology, Chonbuk National University

Wen, Ming-Yu

Department of Housing Environmental Design, and Research Institute of Human Ecology, College of Human Ecology, Chonbuk National University

Cheon, Sang-Hun

R\&D Center, Samhwa Paints Inc. Co., Ltd.

Kang, Chun-Won

Department of Housing Environmental Design, and Research Institute of Human Ecology, College of Human Ecology, Chonbuk National University

他

https://doi.org/10.5109/1526301

出版情報：九州大学大学院農学研究院紀要. 60 (1)，pp. 183-189，2015-02-27. Faculty of Agriculture, Kyushu University

バージョン :

権利関係 : 


\title{
Fire Retardant Performance and Thermal Degradation of Korean Pine Treated with Fire Retardant Chemical
}

\author{
Hee-Jun Park ${ }^{1}$, Ming-Yu Wen ${ }^{1 *}$, Sang-Hun Cheon ${ }^{2}$, \\ Chun-Won KANG ${ }^{1}$ and Junji MATSUMURA
}

\author{
Laboratory of Wood Science, Department of Forest and Forest Product Science, \\ Faculty of Agriculture, Kyushu University, Fukuoka 812-8581, Japann \\ (Received October 29, 2014 and accepted November 14, 2014)
}

\begin{abstract}
An intumescent fire retardant was synthesized with of ammonium phosphate polymer (APP), guanyl urea phosphate (GUP) as main components. And Korean pine (Pinus koraiensis) was impregnated with this fire retardant by a vacuum-pressure process. The fire retardant performance of treated Korean pine wood with various chemical uptakes was assessed by cone calorimeter. The combustion parameters, including heating release rate (HRR), total heat release (THR), effective heat of combustion (EHC), total mass loss (TML), smoke production rate (SPR) and yield of $\mathrm{CO}(\mathrm{CO}$ Y) were recorded simultaneously. To trace the combustion behavior, thermal degradation behavior was analyzed by thermogravimetry (TG). The results indicated that when the uptake of fire retardant chemical above $0.118 \mathrm{~g} / \mathrm{cm}^{3}$, treated Korean pine wood could meet the fire retardant criterion. Heat release was lowered and heat release rate slow down significantly. TG analysis showed that fire retardant treatment increased thermal stabilization, accelerated carbonization and lowered the decomposition temperature of $\operatorname{wood}\left(<300^{\circ} \mathrm{C}\right)$. Wood cellulose decomposed toward carbonation direction at lower temperature, producing more char and correspondingly less flammable volatiles.
\end{abstract}

Key words: combustion behaviors, fire retardant properties, cone calorimeter, thermal degradation

\section{INTRODUCTION}

Wood has many inherently beneficial properties, such as renewability, a high strength to weight ratio, thermal and sound insulation, and low cost, which make it a preferred building material and always is favored in the field of residential, commercial and industry building construction, as well as for indoor furnishing. However, due to wood and wood based materials are mainly composed of cellulose, lignin and hemicellulose, they are combustible. If no fire retardant treatment they are susceptible to fire and burn vigorously, which is an undesirable properties causing huge loss of life and property (Chunang et al., 2008).

Chemical treatment can significantly improve the fire performance of wood materials, thus, it widens their utilization options. Impregnating fire retardant chemicals into the wood is one of major ways to enhance the fire performance of wood. It is well known that wood treated with compounds containing nitrogen, phosphorus, halogens, and boron such as ammonium phosphate, ammonium halide, boric acid and borax to improve fire retardant performance and accelerate the formation of a carbonized layer on the materials (Ayrilmis et al., 2012). Atar and Keskin (2007) impregnated Uludag fir with boric and borax compounds by vacuum technique, and determine the effect of vanishing after impregnation on com-

\footnotetext{
1 Department of Housing Environmental Design, and Research Institute of Human Ecology, College of Human Ecology, Chonbuk National University, Jeonju 561-756, Korea

2 R\&D Center, Samhwa Paints Inc. Co., Ltd., 677 Seonggokdong, Danwon-gu. Ansan 425-835, Korea

* Corresponding author Ming-Yu Wen (E-mail: jlwenmingyu @163.com)
}

bustion properties. Lee et al. (2004) developed a phosphorous pentoxide -amine system and characterized phosphoramide-react wood. And the fire retardant property was also evaluated by DSC and TGA. Ammonium phosphate polymer (APP) and guanyl urea phosphate (GUP) are proven effective fire retardant chemicals. Wang et al. (2005) synthesized a fire retardant chemical (FRW) with main component of GUP and boric, and investigated the fire retardant synergism between them as well as the effect of post-treatment drying method on the bonding strength of the wood. Gao et al. (2006a; 2006b) synthesized a GUP and boric acid, and then determined the GUP compound fire retardant. And the further study the thermal degradation of wood treated with this guanidine compound.

Intumescent fire retardant was intensively concerned owning to its high efficiency and low toxicity. And it was widely applied in polypropylene (PP), Polyoxymethylene (POM) and Ethylene-Vinyl Acetate copolymer (EVA) (Bugajny et al., 1999; Li and He, 2004; Li and Xu, 2006). Typical formulations of intumescent flame retardants contained an acid agent, a carbon source and a blowing agent. The most common carbon sources are polyols such as penthaerythritol. However, there are some disadvantages associated with those fire retardant chemicals such as acidic or weak acidic ultimate $\mathrm{pH}$ value, high hygroscopicity and hoarfrost occurred on the surface of wood due to the high hygroscopic fire retardant chemicals migrating on to surface, which shorten wood materials service life and affect the natural wood surface beauty.

The fire performances of fire retardant treated wood and wood-based materials have been studied extensively and evaluated mainly based on heat release performances using cone calorimeter test and thermogravimetry 
analysis (TGA)(Gao et al., 2009; Harada et al., 2009; Harada et al., 2003; Hirata et al., 1991). Actually, the cone calorimeter technique provides detailed information on heat release, mass loss and smoke production during sustained combustion, and some key parameters, which correlate well with an actual fire. However, only a few studies have systematically conducted cone calorimeter test.

In this study, an intumescent fire retardant chemical was synthesized to solve above mentioned problems and was applied in impregnation of Korean pine (Pinus koraiensis). During combustion, by this intumescent fire retardant system, APP and GUP act as acid and blowing agent and wood material provide carbon resource because of their ability to form a carbon layer when degraded. The fire retardant performance with different chemical uptakes was evaluated using cone calorimeter including the parameters of heat release (total heat release, THR; heat release rate, HRR; effective heat of combustion, EHC), mass loss (total mass loss, TML) as well as gas and smoke release (smoke production rate, SPR; yield of CO, $\mathrm{CO} \mathrm{Y}$ ), and the quantity needed to meet the fire retardant requirement for application was determined. In addition, to obtain more information regarding the fire retardant effect after treatment with the new fire retardant chemical, thermal degradation was analyzed using TGA.

\section{MATERIALS AND METHODS}

\section{Wood specimen}

Korean Pine (Pinus koraiensis) was cut into the samples with the dimension of 910 (longitudinal) $\times 100$ (tangential) $\times 10$ (radial) $\mathrm{mm}$ for fire retardant treatment. Defect free regular boards with similar weight were selected. Prior to treatment, boards with the air-dried density of $0.40 \mathrm{~g} / \mathrm{cm}^{3}$ were kiln-dried to $8 \%$ moisture content (MC), and then labeled and weighed.

\section{Synthesis of fire retardant chemical}

In the first stage, APP derivates was synthesized by reaction of phosphate acid and urea. Molar ratio is 1:1.8. Firstly phosphate acid and urea reacted into milk color at $100^{\circ} \mathrm{C}$. And then temperature was heated to $150^{\circ} \mathrm{C}$, and reaction continued until the milk color change into transparent color. Total reaction time was approximately $1 \mathrm{~h}$. When temperature was cooled down to room temperature, 25wt.\% GUP solution was added into the APP derivates solution with 5 wt.\% mass ratio and mixed evenly.

In the second stage 10wt.\% dimethyl ethanol amine (DMEA) was added into 15wt.\% acrylamide-acrylic acid$\mathrm{N}$ - \{3-(dimethylamino) propyl $\}$ methacrylamide copolymer solution with 0.05 to $1.0 \%$ mass ratio. And $\mathrm{pH}$ value was adjusted 7 to 8 . The mixture was added into first stage APP and GUP mixture with agitation. Then antiseptic 2- benzisotiazolin-3-one and antifreeze ethylene was added. The resultant fire retardant chemical is of $25 \%$ concentration, a specific gravity of $1.13\left(20 \pm 2^{\circ} \mathrm{C}\right)$ and a $\mathrm{pH}$ of $7.6\left(20 \pm 2^{\circ} \mathrm{C}\right)$.

\section{Fire retardant treatment}

Wood samples were randomly placed in a vertical cylindrical vessel. A vacuum of $-0.098 \mathrm{MPa}$ was applied for $10 \mathrm{~min}$ for removing the air contained within wood, then the fire retardant chemicals refluxed into the vessel and the pressure was raised to $1.5 \mathrm{MPa}$ and maintained for $30 \mathrm{~min}$. The pressure process was repeated as above with a 30 min interval. Then, samples were weight and mass increases were determined from the mass difference between pre-treated and treated boards. After impregnation, the samples were air dried for two weeks and then dried at $60^{\circ} \mathrm{C}$ to a $\mathrm{MC}$ of $12 \%$.

\section{Characterization of fire retardant treated wood Chemical uptake}

The amount of FR chemical absorbed by the wood sample was calculated by uptake as follows: uptake (g/ $\left.\mathrm{cm}^{3}\right)=(\mathrm{Mt}-\mathrm{Mu}) / \mathrm{V}$, where $(\mathrm{Mt}-\mathrm{Mu})$ is the mass (gram) of FR chemical absorbed and $\mathrm{V}$ is the volume of sample in $\mathrm{cm}^{3}$.

\section{Specific gravity}

After treatment the boards with different FR uptake were cut into $50 \times 50 \times 10 \mathrm{~mm}$ samples, oven-dried at $103^{\circ} \mathrm{C}\left( \pm 2^{\circ} \mathrm{C}\right)$ until no mass change was observed and cooled down in the desiccators. Then the length, width and thickness were measured with a micrometer (accurate to \pm 0.1 ). The specific gravity of the samples was calculated based on the oven-dry mass and green volume. Void volume filled (VVF)

Based on the assumption that within the given volume of the sample with known basic density and constant cell wall density $\left(1500 \mathrm{~kg} / \mathrm{m}^{3}\right)$, there will be a void volume basically composed of cell lumina, intercellular spaces, and penetrable cell wall voids, which can be filed by liquids(Ahmed et al., 2011; Ahmed et al., 2013). The porosity as void volume (P) and void volume filled (VVF) of wood samples were calculated as follows:

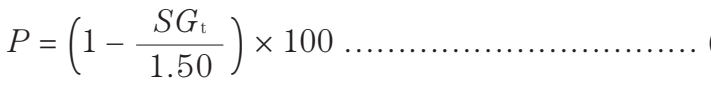

$$
\begin{aligned}
& V V F=\left(\frac{M_{\mathrm{t}}-M_{\mathrm{u}}}{V \times P}\right) \times 100
\end{aligned}
$$

where, SGt is the specific gravity of the treated sample, Mt (g) is the mass of treated sample, and $\mathrm{Mu}(\mathrm{g})$ is the mass of the untreated sample. $\mathrm{V}\left(\mathrm{cm}^{3}\right)$ is the volume of sample before oven drying with 12\% MC.

\section{Cone calorimeter test}

The samples were selected with chemical increases of approximately 150, 250, 350 and $550 \mathrm{~g}$ corresponding to the uptake of $0.053,0.088,0.118$ and $0.195 \mathrm{~g} / \mathrm{cm}^{3}$, respectively. The fire retardant performances of samples were assessed using the cone calorimeter according to ISO 5660-1 with three replicated experiments. The surface heated area of sample was $100 \times 100 \mathrm{~mm}$ and exposed horizontally at the heat flux of $50 \mathrm{~kW} / \mathrm{m}^{2}$. The heating time is $10 \mathrm{~min}$. The following parameters were deter- 
mined: THR, HRR, EHC, TML, SPR and CO Y.

\section{Thermogravimetry analysis}

For thermal analysis, the samples were milled to pass through 50 meshes size, and the sample weight was approximately $5 \mathrm{mg}$. TG was conducted on a TG instrument (SDT-Q600 V20.9), under a dynamic nitrogen (dried) atmosphere at a heating rate of $10^{\circ} \mathrm{C} / \mathrm{min}$. The temperature range was from ambient to $600^{\circ} \mathrm{C}$.

\section{RESULTS AND DISCUSSION}

\section{Cone Calorimetry test}

\section{Heat release}

The THR, HRR and EHC topical curves of samples were shown in Figs. 1-3. The THR at $300 \mathrm{~s}$ and $600 \mathrm{~s}$, peak of HRR, and the time of Pk HRR are given in Table 1. The THR and HRR measurements are the quantity of most concern in predicting the course of the fire and its effect. The slope of the THR curve can be assumed as representative of fire spread. The lower the THR value is, the safer the material is. As shown Fig.1, the slope of samples decreased as fire retardant (FR) uptake increased. When the uptake was up to $0.118 \mathrm{~g} / \mathrm{cm}^{3}$, THR values were 1.05 and $6.24 \mathrm{MJ} / \mathrm{m}^{2}$ at $300 \mathrm{~s}$ and $600 \mathrm{~s} \mathrm{respec-}$ tively. Both values were below $8 \mathrm{MJ} / \mathrm{m}^{2}$, indicating that the pine wood met the fire-retardant and quasi- noncombustible requirements according to Building finishing materials fire retardant and fire spreading prevention rescue standard of Korea.

HRR is a very important parameter used to express the intensity of a fire(Wu et al., 2012). Usually, it was recognized to quantify the size of fire. A highly fire retardant system normally shows a low HRR value. As shown in Fig. 2, it is apparent that HRR curve exhibits two main peaks when pine wood with an uptake below $0.118 \mathrm{~g} / \mathrm{cm}^{3}$. The first peak is assigned to the ignition and to the spread on the surface of the material and then, the second peak is explained by the destruction of the fire retardant chemicals and the formation of a carbonaceous residue. When uptake was below $0.118 \mathrm{~g} / \mathrm{cm}^{3}$, the fire retardant effect was inadequate, since more heat was released in a shorter time below $300^{\circ} \mathrm{C}$. However, the first peak disappeared, and second peak was narrow in shape at a relatively high temperature with the uptake of $0.118 \mathrm{~g} / \mathrm{cm}^{3}$ and disappeared with the uptake of $0.195 \mathrm{~g} /$ $\mathrm{cm}^{3}$. It is considered that the low amount of heat release at a low temperature makes it difficult for the Korean pine wood substrate to reach high temperature.

In addition, compared with the uptake of $0.053 \mathrm{~g} /$ $\mathrm{cm}^{3}$, for $0.118 \mathrm{~g} / \mathrm{cm}^{3}$ and $0.195 \mathrm{~g} / \mathrm{cm}^{3}$ of $\mathrm{FR}$ uptake, THR and HRR decreased approximately $80-85 \%$ and $47-70 \%$, respectively, as shown in Table.1. The HRR peak, which is the most significant parameter when identify the enhancement of fire retardant, decreased by $52-145 \%$. Meanwhile, the peak HRR time was delayed considerably as uptake increased from 0.088 to $0.195 \mathrm{~g} / \mathrm{cm}^{3}$, which contributed to the superior durability of char formed under

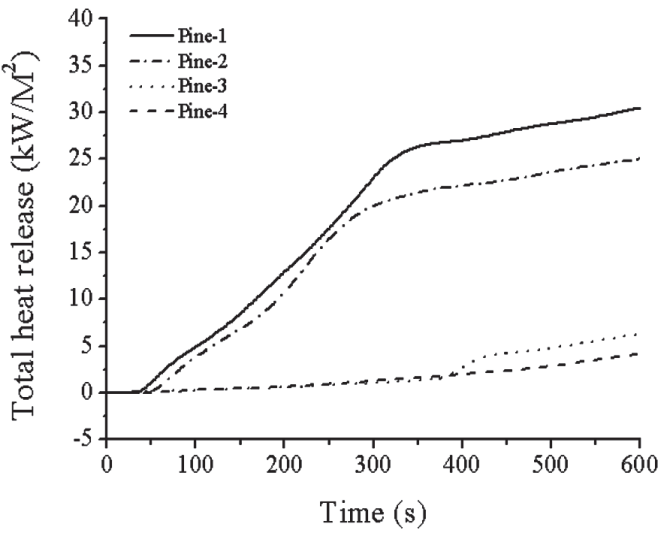

Fig. 1. Total heat release (THR) curves of samples.

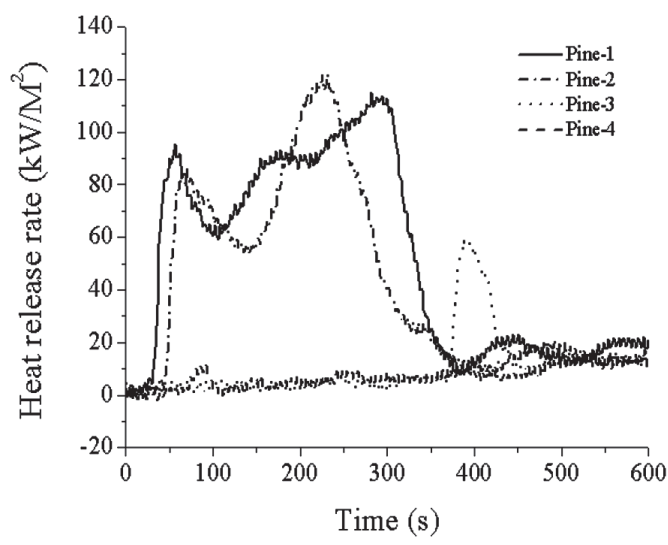

Fig. 2. Heat release rate (HRR) curves of samples.

Table 1. Combustion parameters of samples

\begin{tabular}{cccccccccc}
\hline $\begin{array}{c}\text { Sample } \\
\text { No. }\end{array}$ & $\begin{array}{c}\text { Upatake } \\
\left(\mathrm{g} / \mathrm{cm}^{3}\right)\end{array}$ & $\begin{array}{c}\text { VVF } \\
(\%)\end{array}$ & $\begin{array}{c}\text { THR } \\
(300 \mathrm{~s}) \\
\left(\mathrm{MJ} / \mathrm{m}^{2}\right)\end{array}$ & $\begin{array}{c}\text { THR } \\
(600 \mathrm{~s}) \\
\left(\mathrm{MJ} / \mathrm{m}^{2}\right)\end{array}$ & $\begin{array}{c}\mathrm{Pk} \mathrm{HRR} \\
\left(\mathrm{kwM}^{2}\right)\end{array}$ & $\begin{array}{c}\text { Time of } \\
\text { Pk HRR } \\
(\mathrm{s})\end{array}$ & $\begin{array}{c}\text { Pk EHC } \\
(\mathrm{MJ} / \mathrm{kg})\end{array}$ & $\begin{array}{c}\text { Pk CO } \\
\text { Yield } \\
(\mathrm{kg} / \mathrm{kg})\end{array}$ & $\begin{array}{c}\text { Max } \\
\text { TML } \\
(\%)\end{array}$ \\
\hline Pine-1 & 0.053 & 12.50 & 23.03 & 30.49 & 114.96 & 282 & 67.75 & 9.97 & 29.01 \\
Pine-2 & 0.088 & 21.58 & 20.00 & 25.03 & 121.98 & 232 & 53.83 & 6.08 & 32.23 \\
Pine-3 & 0.118 & 31.48 & 1.05 & 6.24 & 59.28 & 388 & 78.17 & 3.90 & 39.44 \\
Pine-4 & 0.195 & 53.84 & 1.26 & 4.18 & 16.71 & 526 & 68.02 & 1.07 \\
\hline
\end{tabular}

Note: (1) VVF, volume of void filled; (2) THR, total heat release; (3) Pk HRR, peak of heat release rate;

(4) Pk EHC, peak of effective heat of combustion; (5) Pk CO, peak of CO yield;

(6) Max TML, maximum total mass loss. 
heating. It is well known that the FR chemicals containing phosphorus can release phosphoric acid which catalyzes the dehydration and carbonization of wood, resulting in formation of less flammable products and correspondingly more char (Zhou et al., 2011). Yunchu et al. (2000) pointed that as for wood materials with carbohydrates, cellulose and hemicelluloses as main component, it can be a carbon source in intumescent fire retardant system, because of their ability to form a carbon layer when degraded. In this intumenscent fire retardant system, APP and GUP as P-N containing chemicals acted as acid source and blowing agent. The fire retardant formed a carbonaceous layer on the surface of wood by dehydration, formation of double bonds, thus initiating cyclization and cross-linking.

$\mathrm{EHC}$, the ratio of total heat release to mass loss, reflects the burning extent of flammable volatiles in gaseous combustion. A higher EHC means the more completely combustion of volatiles (Gao et al., 2005; Gao et al., 2006b). Fig. 3, showed that a large EHC peak appeared after $300^{\circ} \mathrm{C}$ during the flame combustion with the FR uptake over $0.118 \mathrm{~g} / \mathrm{cm}^{3}$. The reason may be that a amount of char formed during the decomposition can cover the surface of the material, hindering the contact between oxygen and underlying material and leading to the incomplete burning of the material, resulting in the lowest EHC value.

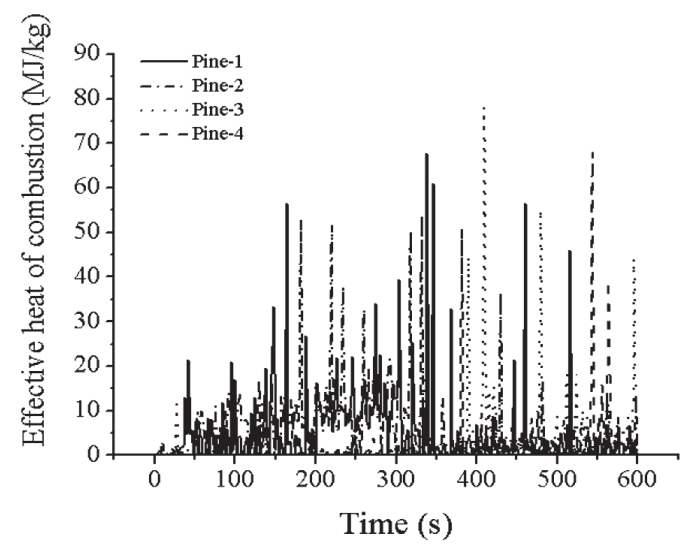

Fig. 3. Effective heat of combustion (EHC) curves of samples.

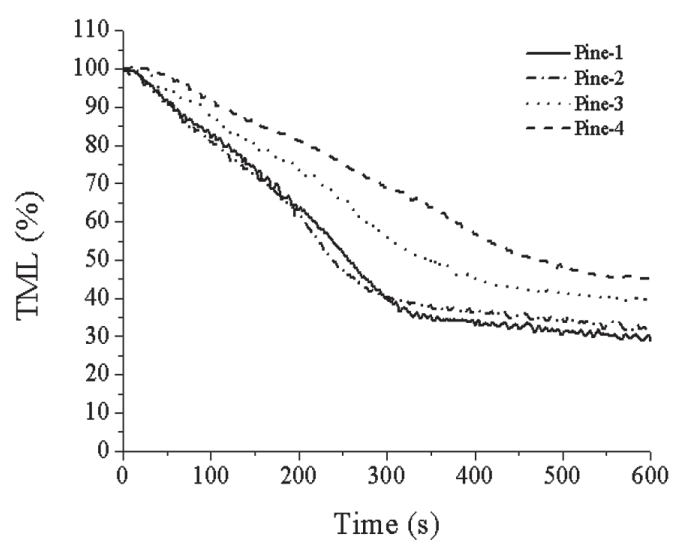

Fig. 4. Total mass loss (TML) profile of samples.
Mass loss

The function of wood fire retardant is to increase the char at the cost of flammable volatile products. The mass residue reflects the char yield. The more mass left, the better the fire retardant. In Fig. 4, the TML curves are similar to the THR curves, indicating that during the combustion heat release accompanied mass loss. The TML gradually decreases as chemical uptake increased. Compared with $29 \%$ residue at $600 \mathrm{~s}$ with $0.053 \mathrm{~g} / \mathrm{cm}^{3}$ uptake, with the uptake of $0.118 \mathrm{~g} / \mathrm{cm}^{3}$ approximately $39.5 \%$ residues remained, and $45 \%$ for $0.195 \mathrm{~g} / \mathrm{cm}^{3}$ uptake was left. It was implied that during the heating process, the fire retardant chemicals generated a cellular charred layer on the surface of the pine wood surface, which protected the underlying wood material from the action of the heat flux or flame and of oxygen toward the wood substrate, which lead to an increase of char residues and correspondingly a decrease in HRR and THR as stated above.

The mechanism of phosphorus-based fire retardant chemicals is often written in terms of simple acid-catalysed, dehydration reaction, as shown in the four reactions as follows:
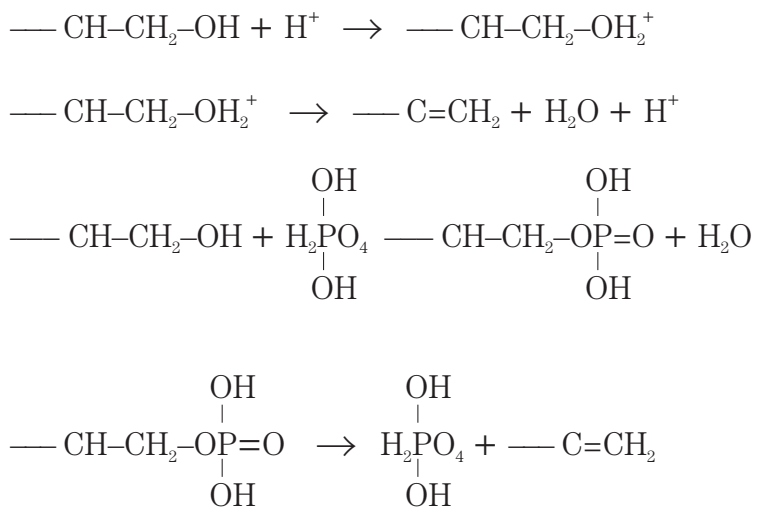

The first two reactions show the depolymerization catalysed by an acid. The second two reactions show the dehydration of the polymer (wood) when phosphoric acid is present. Both of those two reactions resulted in producing $-\mathrm{CH}=\mathrm{CH}_{2}$ fragments at the polymer (wood) chain ends, and then condensed to form carbon char residues. Gas and smoke release

SPR is the smoke produced instantaneously and calculated by multiplying a specific extinction area by MLR. The SPR of samples with different FR uptake as a function of time is shown in Fig. 5. Smoke is formed first at the beginning of burning and decreased prior to the end of burning. The first peak was formed at the beginning of burning and the second peak appeared prior to the end of burning. The effect of the fire retardant chemical on smoke is apparent. The first peak was decreased by $63-72 \%$, compared with the uptake below and above $0.118 \mathrm{~g} / \mathrm{cm}^{3}$. A significant fire retardant effect was obtained with an increasing chemical uptake. This may be attributed to the competition between the char-forming fire retardant action and evolution of combustible gases. When pine wood was heated, GUP and APP 
decomposed and then produced incombustible materials such as $\mathrm{NH}_{3}$ and $\mathrm{CO}_{2}$ to barrier or dilute oxygen of combustible gases. APP and GUP decomposed to produce phosphoric acid, HPO, and PO radicals, which are considered to be free radical scavengers. Thus, HPO and PO can trap the free radicals produced from wood.

In addition, the majority smoke was produced during flame combustion. The increased smoke with lower fire retardant chemical uptake can be explained by the enlarged flame combustion which caused the pyrolysis rate to suppress the combustion rate, and consequently a portion of pyrolysis degradation products underwent

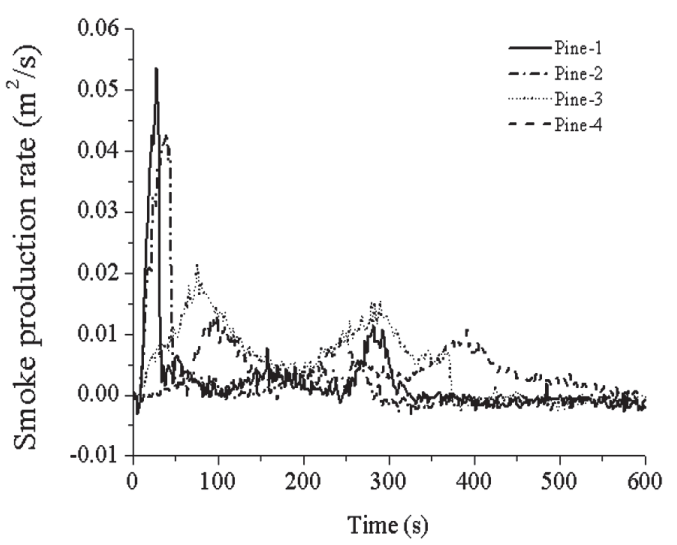

Fig. 5. Smoke production rate (SPR) profile of samples.

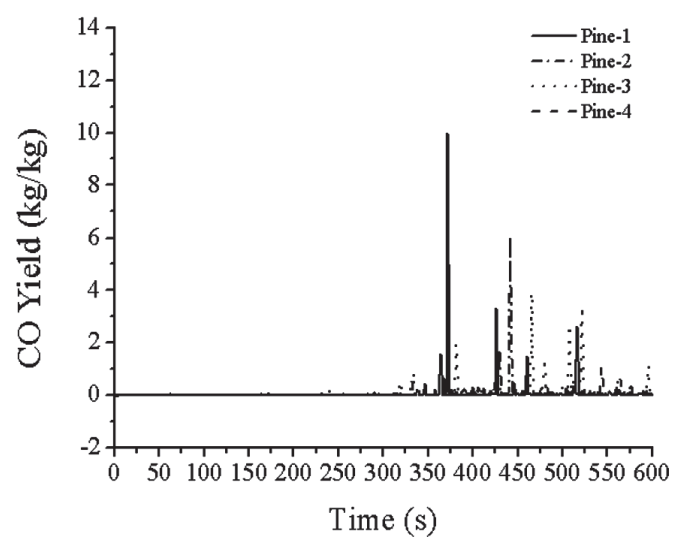

Fig. 6. CO yield (CO Y) profile of samples. an incomplete burn or no burn, and then was exhausted. The fire retardant treatment can decrease the pyrolysis, thus the pyrolysis product can be burned completely, and the smoke decreased (Chiu and Wang, 1998).

Generally, the smoke production and toxic gas formation during wood combustion play a key role in the fire condition. Particularly CO is one of most toxic gas released in terms of wood materials. Actually, as shown in Table 1 and Fig. 6 peak CO yield increased as FR uptake increased and trended to appear at high temperature. The formation of CO in fire occurs at low temperature in the early stage of fire development mainly due to incomplete combustion of pyrolysed fuel volatiles (Chuang et al., 2013).

Thermogravimetry analysis

As stated above, when the FR uptake was up to $0.118 \mathrm{~g} / \mathrm{cm}^{3}$, the fire retardant performance were improved significantly. Thus the uptake of $0.118 \mathrm{~g} / \mathrm{cm}^{3}$ was fixed for TG analysis to investigate further the thermal stability of treated Korean pine samples. Thermal degradation data of Korean pine wood is presented in Table. 2.

Wood consists of three main components: cellulose, hemicelluloses and lignin. Cellulose amounts to 50\% of weight of wood. Lignin and hemicelluloses in conifer tree species vary from $25 \%$ to $35 \%$ and from $15 \%$ to $20 \%$, respectively. Hirata et al. (1991) reported that cellulose begins to lose weight at temperature above $300^{\circ} \mathrm{C}$ and most rapidly completes loss to yield the least amount of char and then the greatest amount of volatiles. Therefore, it is the cellulose that causes and feeds flaming combustion by the process that high pyrolysis rate overcomes the diffusion rate of the volatiles produced and concentrates them. Of the tree components, it is proposed that the thermal degradation of hemicelluloses occurs firstly, while cellulose then thermally decomposes through 2 competing pathways. At lower temperatures $\left(<300^{\circ} \mathrm{C}\right)$, there is a gradual degradation which includes dehydraton, depolymerization, oxidation, and carbonization, and then results carbon monoxide, carbon dioxide, and formation of carbonyl and carboxyl groups and ultimately forms a carbonaceous residue. At higher temperatures $\left(>300^{\circ} \mathrm{C}\right)$, a rapid volatilization occurs via the formation of levoglucosan which can be further decomposed into more volatile and flammable products, as shown in Fig. 7

Table 2. Thermal degradation data of Korean pine wood by thermogravimetric analysis (TGA)

\begin{tabular}{cccccc}
\hline \multirow{2}{*}{ Sample } & Stage & $\begin{array}{c}\text { Temperature } \\
\text { Rang }\left({ }^{\circ} \mathrm{C}\right)\end{array}$ & $\begin{array}{c}\text { Mass loss } \\
(\%)\end{array}$ & $\begin{array}{c}\text { DTG } \\
\text { maximum }\left({ }^{\circ} \mathrm{C}\right)\end{array}$ & $\begin{array}{c}\text { Residue } \\
(\%)\end{array}$ \\
\hline \multirow{2}{*}{$\mathrm{P}-\mathrm{C}$} & Drying step & $220-314$ & 18 & & 368 \\
& Charring step & $314-423$ & 56 & 9 & 32.7 \\
& Calcining step & $423--$ & 13 & 269 & 33.2 \\
\hline \multirow{2}{*}{$\mathrm{P}-\mathrm{T}$} & Drying step & $150-239$ & 20 & & \\
& Charring step & $239-316$ & 28 & & \\
\hline
\end{tabular}

Note: (1) P-C, control Korean Pine; P-T, treated Korean Pine

(2) DTG, derivative thermogravimetric analysis 
(Kawamoto et al., 2008; Li and He, 2004).

The TG curves in Fig. 8 showed that wood underwent three weight loss phases during heating process: drying phase, charring phase and calcining phase both of untreated and treated pine wood samples. The rapid decomposition temperature decreased from $368^{\circ} \mathrm{C}$ to $269^{\circ} \mathrm{C}$, and the mass residue increased from $12.7 \%$ to $33.2 \%$. For the untreated pine sample, there was a mass loss of $18 \%$ in the $220-314^{\circ} \mathrm{C}$ temperature range in drying phase, which is due to the decomposition or dehydration of hemicelluloses. For the charring phase, 56\% mass loss occurred in the $314-423^{\circ} \mathrm{C}$ temperature range, which is due to the decomposition of cellulose. 9\% mass loss in the calcining at $423-600^{\circ} \mathrm{C}$. For treated pine, a mass loss of $13 \%$ in the $150-239^{\circ} \mathrm{C}$ temperature range in the drying phase occurred. It is suggested that the initial reaction is due to the release of phosphoric acid of the samples. These released acids then catalyze the decomposition or dehydration of hemicelluloses. For the charring phase, $19 \%$ mass loss occurred in the temperature range 239$316^{\circ} \mathrm{C}$ due to acid-catalyzed decomposition of cellulose and hemicellulose, which corresponds to the shoulder and the larger peak in DTG curve at $269^{\circ} \mathrm{C}$. After the charring phase, $28 \%$ mass loss of the residual materials of wood were found to be slow in the temperature range 316$600^{\circ} \mathrm{C}$. Based on the above analysis, after fire retardant treatment wood burn tends to be steady and thermal degradation temperature was lowered.

For the thermal degradation of the pine sample treated with APP and GUP, compared with that of the untreated pine sample, there are some variations as follows:

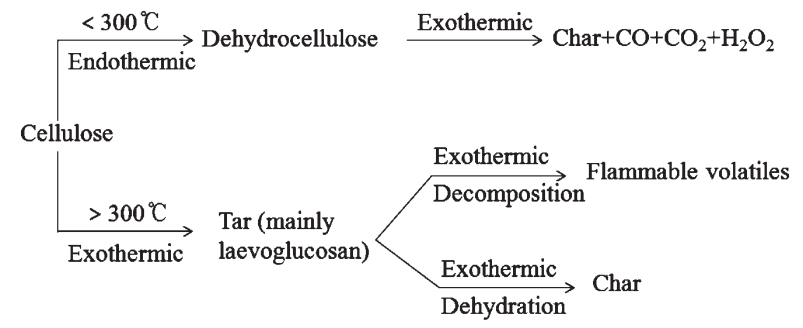

Fig. 7. Stages in the pyrolysis of cellulose.

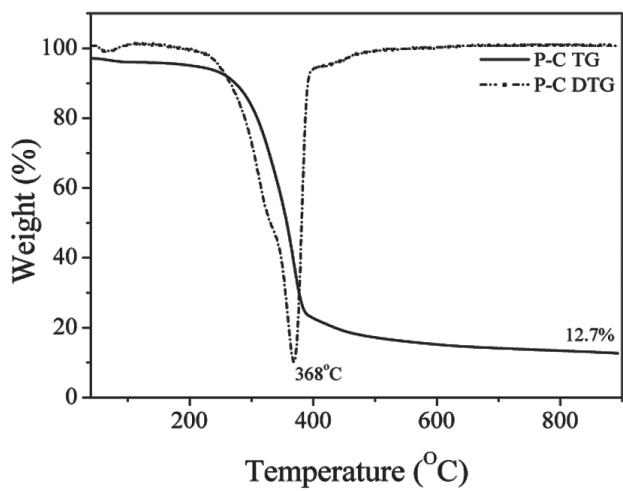

Initial decomposition was lowered, from $220^{\circ} \mathrm{C}$ to 150 , which is due to the dephosphorylation and catalytic dehydration of treated pine sample. As shown in TG cures, apparent thermal degradation occurred at the $150-239^{\circ} \mathrm{C}$. And there is narrow peak in this temperature rang at DTG curve.

Main thermal decomposition stage advanced approximately $70^{\circ} \mathrm{C}$, indicating that fire retardant chemicals catalyzed Korean pine wood decomposition and caused the thermal decomposition occurred below $300^{\circ} \mathrm{C}$.

Mass loss decreased approximately 36\% during the main thermal decomposition, indicating that remained residue char was increased. It confirmed that the cellulose decomposed toward carbonation direction at lower temperature, producing more char and correspondingly less flammable volatiles. Consequently, addition of the fire retardant chemicals caused the thermal degradation of Korean pine wood to occur earlier and promote char formation

\section{CONCLUSION}

Cone Calorimetry proved that fire performance including heat release, mass loss, gas and smoke release of Korean pine were enhanced by fire retardant treatment and increased with increasing the FR uptake. When the uptake increased from $0.053 \mathrm{~g} / \mathrm{cm}^{3}$ to $0.118 \mathrm{~g} / \mathrm{cm}^{3}$, the THR and HRR was decreased by $80-85 \%$ and $47-70 \%$, respectively. At an uptake above $0.118 \mathrm{~g} / \mathrm{cm}^{3}$, the treated Korea pine wood met the fire retardant requirement. The TML gradually decreased as FR uptake increased, and higher residue remained. The peak of SPR and CO $\mathrm{Y}$ was decreased, indicating less gas and smoke release.

The TG analysis verified that fire retardant chemical with the APP, GUP and phosphonic acid as main components treatment effectively accelerated dehydration and carbonization of wood, increased thermal stabilization of wood and lowered the decomposition temperature $(<$ $300^{\circ} \mathrm{C}$ ). Consequently, more char and less flammable volatile products resulted, and a better fire retardant performance was obtained.

\section{ACKOWLEDGEMENT}

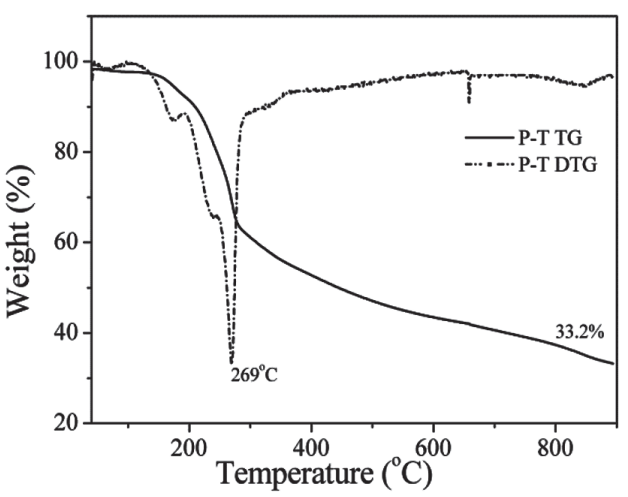

Fig. 8. Thermogravimetry (TG) and DTG curves of Korean pine without and with treatment (P-C, pine control; P-T, pine treatment). 
This paper was supported by research funds of Chonbuk National University in 2014.

\section{REFERENCES}

Ahmed, S., M. Sehlstedt-Persson, L. Hansson and T. Morén 2013 Evaluation of preservative distribution in thermally modified European aspen and birch boards using computed tomography and scanning electron microscopy. $J$ Wood Sci. 59(1): 57-66

Atar, M. and H. Keskin 2007 Impacts of coating with various varnishes after impregnation with boron compounds on the combustion properties of Uludag fir. J Appl Polym Sci. 106(6): 4018-4023

Ayrilmis, N., J. Benthien, H. Thoemen and R. White 2012 Effects of fire retardants on physical, mechanical, and fire properties of flat-pressed WPCs. Eur J Wood Prod. 70(1-3): 215-224

Bugajny, M., S. Bourbigot, M. Le Bra and R Delobel 1999 The origin and nature of flame retardance in ethylene-vinyl acetate copolymers containing hostaflam AP 750. Polym Int. 48(4): $264-270$

Chiu, S.-H. and W.-K. Wang $1998 \mathrm{~T}$ he dynamic flammability and toxicity of magnesium hydroxide filled intumescent fire retardant polypropylene. J Appl Polym Sci. 67(6): 989-995

Chuang, C.-S., K.-C. Tsai, M.-K. Wang, C.-C. Ou, C.-H. Ko and I.-L. Shiau 2008 Effects of intumescent formulation for acrylic-based coating on flame-retardancy of painted red lauan (Parashorea spp.) thin plywood. Wood Sci Technol. 42(7): 593-607

Chuang, C.-S., T.-H. Yang, K.-C. Tsai, T.-Y. Tseng and M.-K. Wang 2013 Fire retardancy and $\mathrm{CO} / \mathrm{CO} 2$ emission of intumescent coatings on thin plywood panel with waterborne vinyl acetateacrylic resin. Wood Sci Technol. 47(2): 353-367

Gao, M., B. Ling, S. Yang and M. Zhao 2005 Flame retardance of wood treated with guanidine compounds characterized by thermal degradation behavior. J Anal Appl Pyrol. 73(1): 151-156

Gao, M., J. Niu and R. Yang 2006a Synergism of GUP and Boric Acid Characterized by Cone Calorimetry and Thermogravimetry. $J$ Fire Sci. 24(6): 499-511

Gao, M., S. Yang and R. Yang 2006b Flame retardant synergism of GUP and boric acid by cone calorimetry. J Appl Polym Sci. 102(6): 5522-5527

Gao, Z., W. Su and D. Wu 2009. Polyurethane-solid wood composites. II. Flammability parameters. J Appl Polym Sci. 113(5):
$3279-3285$

Harada, T., H. Matsunaga, Y. Kataoka, M. Kiguchi, and J. Matsumura 2009 Weatherability and combustibility of fire-retardantimpregnated wood after accelerated weathering tests. $J$ Wood Sci. 55 (5): 359-366

Harada, T., S. Uesugi and T. Taniuchi 2003 Evaluation of fireretardant wood treated with poly-phosphatic carbamate using a cone calorimeter. Forest Prod J. 53(6): 81-85

Hirata, T., S. Kawamoto, T. Nishimoto 1991 Thermogravimetry of wood treated with water-insoluble retardants and a proposal for development of fire-retardant wood materials. Fire Mater. 15(1): 27-36

Kawamoto, H., D. Yamamoto and S. Saka 2008 Influence of neutral inorganic chlorides on primary and secondary char formation from cellulose. J Wood Sci. 54(3): 242-246

Lee, H.-L., G. C. Chenand , R. M. Rowell 2004 Thermal properties of wood reacted with a phosphorus pentoxide-amine system. J Appl Polym Sci. 91(4): 2465-2481

Li, B. and J. He 2004 Investigation of mechanical property, flame retardancy and thermal degradation of LLDPE-wood-fibre composites. Polym Degrad Stabil. 83(2): 241-246

$\mathrm{Li}, \mathrm{B}$. and M. Xu 2006 Effect of a novel charring-foaming agent on flame retardancy and thermal degradation of intumescent flame retardant polypropylene. Polym Degrad Stabil. 91(6): $1380-1386$

Wang, Q., J. Li and J. Winandy 2004 Chemical mechanism of fire retardance of boric acid on wood. Wood Sci and Technol. 38(5): 375-389

Wang, Q., W. Wang and J. E. Winandy 2005 Effect of new GUP-B fire retardant on mechanical properties of Korean pine when exposed to elevated temperature. Forest Prod J. 55(12) 214-220

Wu, X., L. Wang, C. Wu, G. Wang and P. Jiang 2012 Flammability of EVA/IFR (APP/PER/ZB system) and EVA/IFR/synergist (CaCO3, NG, and EG) composites. J Appl Polym Sci. 126(6): $1917-1928$

Yunchu, H., Z. Peijang and Q. Songsheng 2000 TG-DTA studies on wood treated with flame-retardants. Holz als Roh-und Werkstoff. 58(1-2): 35-38

Zhou, L., C. Guo and L. Li 2011 Influence of ammonium polyphosphate modified with 3-(methylacryloxyl) propyltrimethoxy silane on mechanical and thermal properties of wood flourpolypropylene composites. J Appl Polym Sci. 122(2): 849-855 